\title{
Child neglect: Statutes, rates, and a neglect diversion model
}

\author{
Kristcha DeGuerre ${ }^{1}$, ID Jessica Strolin-Goltzman ${ }^{2}$, Katharine Briar-Lawson ${ }^{1}$ and Brenda Gooley ${ }^{3}$ \\ ${ }^{1}$ School of Social Work, State University of New York, University at Albany \\ ${ }^{2}$ College of Education and Social Services, University of Vermont \\ ${ }^{3}$ Department for Children and Families, Family Services Division, State of Vermont
}

Received 14 August 2021

Accepted for publication 3 November 2021

Published 18 December 2021

\begin{abstract}
Poverty is a correlate, if not a cause, of child neglect in the US and worldwide. Using a multi-phased analysis, we examined US state statutes on neglect to classify differing attributes of neglect across states. Focusing on the states that use poverty and service access qualifiers in their neglect statutes, we compared their neglect rates with states that do not include such qualifiers. We hypothesized that states with poverty exemptions would have proportionately fewer neglect cases. Our findings did not support the hypothesis. However, they did expose the wide variation in neglect rates in states across the nation, ranging from $92.2 \%$ to $1.5 \%$. Using Vermont as a case study, with the lowest reported screened in neglect cases, we explored the extent to which Vermont could be seen as a positive outlier. We found diversion and related practices helped to explain the low rate of screened in neglect cases. These include the use of an economic firewall with poverty-related cases in Vermont being referred to economic services instead of a CPS investigation, co-location of child welfare services with economic services, the use of Parent-Child Centers, and Differential Response Systems.
\end{abstract}

Keywords: child welfare, poverty, neglect, racial and ethnic differences, diversion

\section{Introduction}

Child neglect is the most prominent type of reported child maltreatment in the U.S. In 2019, $61 \%$ of all screened in maltreatment cases were classified as child neglect (US Department of Health and Human Services, 2021; Sciamanna, 2019). Poverty is highly correlated with child maltreatment, particularly neglect (Child Welfare Information Gateway [CWIG], 2018; Houshyar, 2014; Milner and Kelly, 2020; Sedlak et al., 2010; Slack, Berger and Noyes, 2017). Most parents living in poverty do not abuse or neglect their children. However, surveillance of the poor by the systems that serve them may increase the likelihood of their being reported to Child Protection Services (CPS) in the U.S. Moreover, in the U.S. racial disparities are prominent in maltreatment cases, reflecting structural inequities in employment, income, community supports, implicit bias in reporting, investigations, and out of home placements (CWIG, 2016). In fact, there are disparities in access to jobs with living wages, child care, and housing, may add to the racial disproportionalities in CPS involvement especially for African American and American Indian children (CWIG, 2016). The COVID-19 pandemic has heightened concerns about neglect cases, expected to be on the rise in the U.S., and there are recent calls to divert neglect cases from the CPS system. As child neglect has become highlighted as the overriding form of maltreatment, more research and investigations are warranted addressing neglect rates, definitions and variance among the states.

This paper addresses the variations in neglect statutes and rates in the U.S. In the U.S., each state creates its own statute. There is no one national definition or set of standards governing how neglect is defined, operationalized, and reported (DeGuerre and Briar-Lawson, 2020). Few, if any, studies have examined the types of neglect statutes and rate variation across the U.S. Thus, this probe represents a research genre that is seen as timely, given fears of a spike in neglect cases due to rising pandemic and post pandemic-related poverty. It is important to recognize that reported and screened 
in rates of child neglect do not reflect the true rates of neglect. Moreover some forms of neglect, like those that are chronic, may incur long lasting harm for the child (Kaplan et al. 2009; Semanchin Jones and Logan-Greene, 2016).

The purpose of this manuscript is to examine the extent to which poverty exemptions in state statutes $(\mathrm{N}=15)$ are correlated with 'screened out' neglect cases. We then undertake a case study of Vermont, the U.S. state with the lowest rate of screened in neglect cases to explore the extent that Vermont can be seen as a 'positive outlier.' Finally, based on a review of rates, statutes, and the case study, we offer recommendations to create more innovative practices to address and divert neglect cases to other systems and services that can more appropriately aid children, parents, and whole families.

\section{Child neglect and poverty}

Leaders at the Children's Bureau in the U.S. have argued that more needs to be done to address poverty and avert families from being relegated to the child welfare system and face possible child removal (Milner and Kelly, 2020). They cite examples of programs that aid families with material needs and also respond to their cultural uniqueness and rights. One example cited by Milner and Kelly (2020) includes a judge requiring the child welfare agency to pay for septic tank repairs to keep a family from having to vacate a property and being separated with an out of the home placement of a child. Given the fact that few child welfare systems have resources to address the material needs of families, including employment, income supports, housing, utilities, child care, and transportation funds, it is not surprising that neglect is confused with poverty (Pelton, 1989). Nonetheless, Fong (2020) found that reports to child welfare agencies from mandated reporters, such as teachers, counselors, doctors, and police officers, are often not motivated by the fear of a child being in imminent danger but by the hope that child welfare services would be able to provide concrete services needed by the family. Families often reported to CPS experience multifaceted needs due to systemic disadvantages, such as inadequate housing, jobs, and child care (Coulton et al., 2007; Fong, 2020; Reich, 2005). These structural disadvantages are seen to create risks to children's health and safety, and are not caused by the parent's individual faults. Yet CPS interventions mostly focus on correcting and responding to abusive and neglectful behaviors and not structural issues involving family poverty and related needs (Fong, 2020). This causes the family to experience an invasive investigation, causing anxiety and trauma; made worse because the many material resources needed are not within the domain of the child welfare system and may not be provided (Fong, 2020).

Child welfare practice in the U.S. once focused on poverty and material needs of families. In fact, since the inception of the Social Security Act of 1935, including Aid to Dependent Children (later becoming Aid to Families with Dependent Children), practice included explicit child welfare services integrated with welfare assistance (Pelton, 1989, 2016). Caseworkers in welfare were able to draw not only on welfare assistance but special needs income support grants to aid families and prevent out of home placements. Such integrative practices, combining income assistance with services, were not without problems. Some welfare workers were seen to be coercive in their practices and required parents use services as a condition of welfare aid. Such coercion was seen to be a violation of rights. Thus, in 1969, federal regulations required the separation of income assistance from services, only to be later rescinded.

Nonetheless, the consequent enactment of the Child Abuse Prevention and Treatment Act (CAPTA) of 1974, providing a national framework for child welfare services along with funding for the newly emerging CPS, created a system of investigations and services without access to income assistance for impoverished families. Meanwhile, being poor, rather than being seen as a risk factor, became increasingly criminalized, especially for neglect (Gustafson, 2011). Even though some CPS systems are co-located with welfare services, now called TANF (Temporary Assistance for Needy Families), there may be little collaboration in family preservation-related supports. There are a few exceptions. For example, one model program developed by David Burns in El Paso County, Colorado, demonstrated that when TANF was used as the family preservation arm of CPS, reports of maltreatment referred to CPS declined by $50 \%$ and out of home placements declined by $40 \%$ (Berns,Briar-Lawson and Kim, 2013).

Moreover, IV-E federal funding waivers involving the use of flexible federal funds for demonstration projects in several states have shown promising benefits when concrete resources and flexible funds are made available to families. IV-E funding includes partial funding for states, territories, and tribes for the cost of providing foster care, adoption, and kinship assistance for children who meet federal criteria for eligibility (Children's Bureau, 2021). However, in the demonstration sites IV-E waiver funds could be used for placement prevention and not just foster care and related out of home services. For example, in Oregon, child welfare offices lacking flexible funds had three times higher placement rates than those with access to flexible funds (US 
Department of Health and Human Services, 2005). Similarly, in Indiana, concrete resources were used for housing, utilities to avert placement, and aid with reunification (Pierce et al., 2018). One main finding involving such flexible fund use through IV-E waivers was that participating states reduced the rate of out-of-home placements (US Department of Health and Human Services, 2005). Most recently federal legislation has made it possible through the Family First Prevention Services Act (FFPSA) to use IV-E funds for addressing parental mental health, addictions, parenting skills and kinship care. However, these IV-E prevention funds cannot be used for concrete services and supports, so greatly needed by families in poverty.

\section{Child neglect and cultural differences}

In the U.S., child welfare system involvement is disproportionately comprised of minoritized families and those living in poverty. One in three children will experience a child welfare investigation by the time they reach adulthood. Over half are Black children (Fong, 2020). Wulczyn, Chen and Hislop (2007) found that neglect is the primary reason for placement in out-of-home care among Black children (Wulczyn, Chen and Hislop, 2007). Moreover, Black children were $300 \%$ times more likely to be placed outside of the home than white children (Padilla and Summers, 2011).

Such racial inequities are currently spurring movements to defund CPS, seen as a racially biased surveillance system (Fong, 2020). The goal of these movements is the abolition of the child welfare system, especially the use of foster care, seen to be causing systematic harm to children and families of color, (Dettlaff et al., 2020). As a result, several child welfare systems across the nation have undertaken race equity agendas, examining the potential for racial bias, especially involving African American and American Indian children (Fluke et al., 2010; Pryce et al., 2019).

Anglo Saxon and Eurocentric cultural norms inform U.S. neglect statutes. This is problematic given the diversity of the U.S. population and high rates of poverty among families of color. Rose and Meezan (1996) found that mothers from different cultures perceived neglect differently with White mothers perceiving norms differently from mothers identifying as black, indigenous, or otherwise minoritized. Friedman and Billick (2014) found that Hispanic parents often report not using car seats for their children because they believe that it would cause their child to feel abandoned by not being in their arms, and cause emotional trauma. Yet a child without a car seat might be reported to CPS. Cultural variations exist among such practices such as leaving infants in the care of young children, which would be seen as neglect (Lansford et al., 2015); or children sharing a bed with others (Levine et al, 1994).

With the passing of the 1978 Indian Child Welfare Act (ICWA), tribal practices can be seen as potentially more culturally contextualized. ICWA requires that an enrolled child and family be referred to the tribe for assessment and services. For example, a family struggling with poverty issues might be given aid and support rather than face an investigation (Day, Tach and Mihalec-Adkins, 2021). Even so, cultural explanations and variations are not addressed in any of the neglect statutes adopted by the states (DeGuerre and Briar-Lawson, 2020).

\section{Methods}

To begin to address the variations in the definitions of child neglect, we examined the neglect statutes of each state including Washington D.C. We explored the shared definitional components and characteristics for neglect statutes. From this analysis, a typology was developed to depict these differences and commonalities between the states and Washington D.C. We also explored the extent to which states with a child neglect statute involving a poverty exemption might have lower rates of screened in child neglect cases. We then examined the variations in rates for screened in child neglect cases for each state, including Washington D.C. Rates of child neglect cases that were screened in varied from to $1.5 \%$ to $92.2 \%$ (Department of Health and Human Services, 2021). Three states were seen as potentially 'positive outliers' with rates below $10 \%$. They are Vermont, Pennsylvania and Hawaii. The 'positive outlier' with the lowest number of screened in child neglect, was Vermont leading us to offer next a case study. This case study explores the unique factors that may be influencing the significantly low rates of screened in child neglect cases in Vermont. Finally, we raise questions about poverty-related neglect cases expected to be on the rise, due to the global COVID-19 pandemic and make suggestions for more attention to economic needs of families in the US, especially families who are minoritized.

\section{Child neglect statutes: A typology}

Child neglect state statutes are used to guide the screening in and investigations of reports to the child welfare system. Our review and classification of statutes across the states regarding neglect found 12 different categories of neglect. These range from the absence of medical, dental, surgical, 
child care, behavioral health services to the failure to provide for basic needs such as food, nutrition (failure to thrive), clothing, education, shelter (homelessness), subsistence. Another involves supervision, guidance, runaway, and control concerns. Specifically the typology developed comprises the following:1) absence of medical, dental, surgical, child care, behavioral health other services; 2) failure to provide for basic needs: food, nutrition, failure to thrive, clothing, education, shelter; 3) lack of appropriate supervision and control of child; 4) failure to protect from sexual abuse, trafficking, physical abuse and other harms; 5) substance abuse: mother's substance abuse, infants test positive for substances; 6) neglect defined as other than poverty (poverty qualifiers and exemptions); 7) caregiving impeded: caregiver incarcerated, hospitalized; or child abandonment; 8) environment: cleanliness, drugs present, drug house, injurious, emotionally traumatic; 9) parental behavioral health: mental illness, developmental disabilities, domestic violence; 10) unlawful granting of custody/adoption;11) risk because siblings were neglected; 12) neglect of child in out of home care.

An additional challenge faced in understanding the complex phenomenon of neglect is that it generally involves acts of omission (Child Welfare Information Gateway, 2019). Thus inaction is substantially more challenging to identify than other forms of child maltreatment involving observable and deliberate acts and harms such as physical and sexual abuse. The effects of child neglect are sometimes not immediately visible. In fact, the adverse effects of emotional neglect may manifest later in a child's development than when the neglect occurred (Grossman et al., 2017).

Fifteen states include as one of their statutes the fact that neglect can only occur if the family has financial means (poverty exemption) or has received assistance and still does not provide the child with what is considered necessary for their health and wellbeing (CWIG, 2019). Statutes include the phrasing of 'not solely due to poverty (CWIG, 2019, p.37,57,64,96),' 'for reasons other than being impoverished' (CWIG, 2019, p.20), and 'although financially able to do so or although offered financial or other means to do so (CWIG, 2019 , p. $21,24,35,46,58,61,77,78,83)$.' In doing so, such statutes attempt to separate child neglect from poverty (CWIG, 2019). This indicates that there are states that recognize the need for poverty qualifiers, to differentiate between poverty and neglect, and to potentially protect families from the criminalization of poverty (DeGuerre and Briar-Lawson, 2020).

\subsection{Poverty exemptions and screened in child neglect rates}

Given the high correlation between poverty and neglect in the U.S., it might have been expected that states with poverty exemptions would have very low rates of neglect. Through the analysis of states with a poverty exemption and the corresponding neglect rates, it was found that there is no correlation between poverty exemptions and a lower rate of child neglect (DeGuerre and Briar-Lawson, 2020). Out of the 15 states with a poverty exemption, the lowest percentage of child neglect among these states was $25.1 \%$ of all their screened in child maltreatment cases. In fact, the neglect rates ranged from $25.1 \%$ to $78.1 \%$ (Department of Health and Human Services, 2021).

Our analysis compared the mean for the group of states with a poverty exemption statute, $(\mathrm{M}=55.57, \mathrm{SD}=15.93$, $\mathrm{SEM}=4.11$ ) to the states without the poverty exemption statute $(\mathrm{M}=54.56, \mathrm{SD}=26.98, \mathrm{SEM}=4.49)$. The results were not significant at $p=0.89$. As can be seen from the graphs below and the statistical test, the means are not significantly different. Thus, it can be inferred that just having a poverty exemption in a statute does not guarantee that poverty-related cases would be screened out and that neglect cases might be sharply reduced.

\section{Figure 1. Neglect rates in States without a poverty exemption}

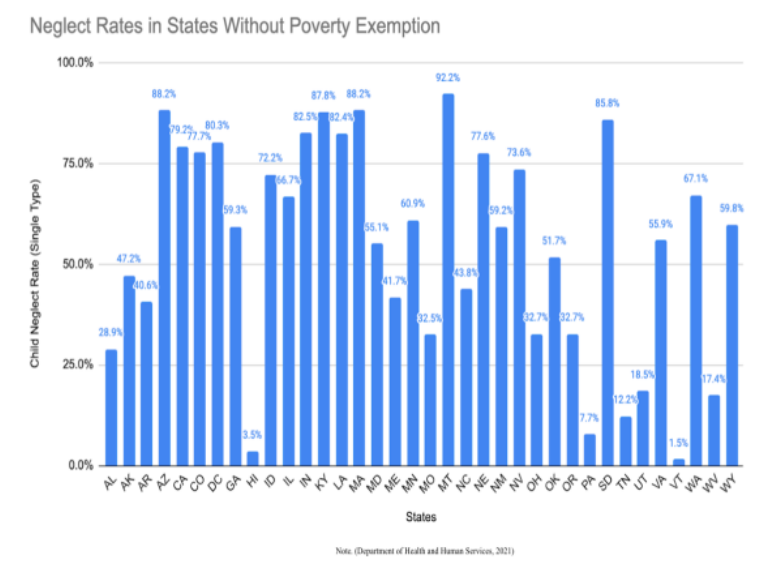

Note: Single type of child neglect rates, excluding medical neglect, from the 2019 Children's Bureau Child Maltreatment Report (Department of Health and Human Services, 2021) 
Figure 2. Neglect rates in States with a poverty exemption

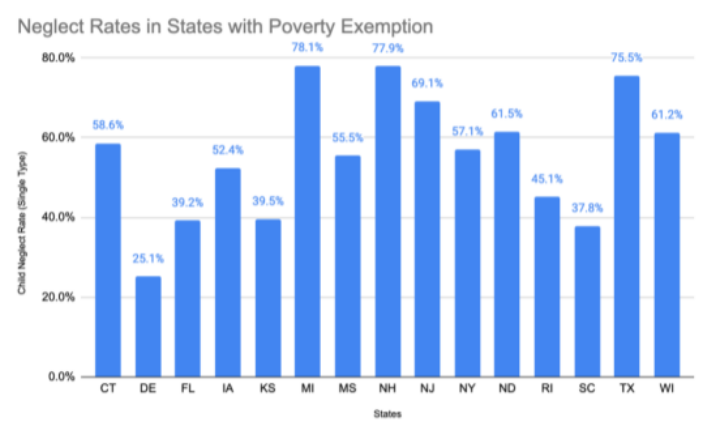

Note: Single type of child neglect rates, excluding medical neglect, from the 2019 Children's Bureau Child Maltreatment Report (Department of Health and Human Services, 2021)

Figure 3. Mean percents of neglect with poverty exemptions and those without poverty exemptions

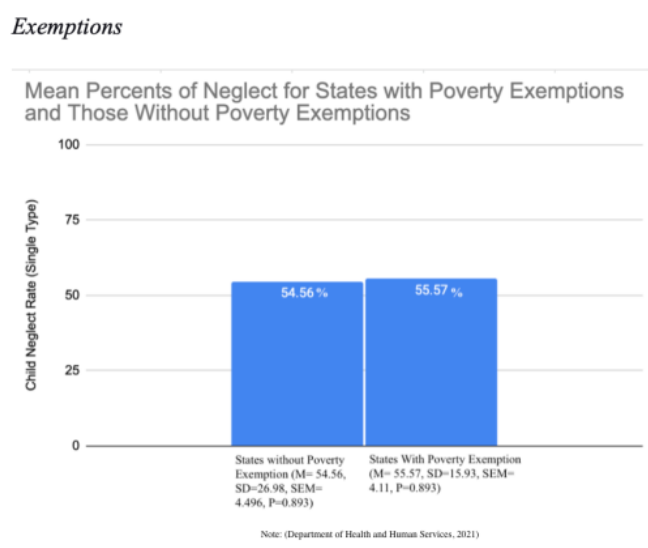

Note: Single type of child neglect rates, excluding medical neglect, from the 2019 Children's Bureau Child Maltreatment Report (Department of Health and Human Services, 2021)

Figure 4. Rates of neglect by State

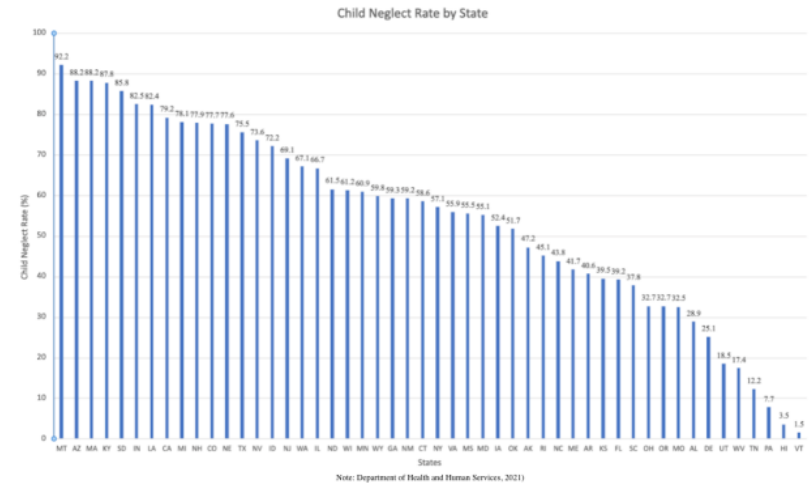

Note: Single type of child neglect rates, excluding medical neglect, from the 2019 Children's Bureau Child Maltreatment Report (Department of Health and Human Services, 2021)

\section{Variations in neglect rates}

The Child Maltreatment Report of 2019 (Department of Health and Human Services, 2021) shows neglect rates ranging from $92.2 \%$ to $1.5 \%$ across the nation. About twothirds of states, including the District of Columbia, indicate $50 \%$ or more of the screened in cases of child maltreatment are comprised of child neglect (DeGuerre and Briar-Lawson, 2020). Vermont's reported rate is $1.5 \%$ for child neglect, versus a national mean of $54.3 \%$. The graph above depicts the variance in neglect rates across the states.

\section{Case study of Vermont: A positive outlier?}

An exploration of administrative data, key informant discussions, and analyses were completed in order to better understand what Vermont is doing differently than other states. The case study that follows describes the population demographics, policies, statutes, organizational structures, and maltreatment data in Vermont. We then identify some possible key lessons derived from the case study that may help to explain how Vermont can be considered a 'positive outlier' involving the lowest rates of screened in neglect cases.

\subsection{Poverty, race, and population demographics}

Given the correlation of poverty with maltreatment and especially child neglect, it is important to examine Vermont poverty and population data. Poverty rates in Vermont have consistently been lower than the national average (Census Bureau, 2020). In 2019, $11 \%$ of the population was designated as living in poverty. Child poverty rates in 2019 were $10 \%$, with Vermont being ranked as $8^{\text {th }}$ lowest in the country (Children's Defense Fund, 2021). One might argue that the lower overall state poverty rate and especially being ranked $8^{\text {th }}$ lowest with a child poverty rate could explain the low screened in neglect rates.

Another possible explanation for low screened in neglect rates might also be related to low percentages of racial and ethnic diversity in Vermont. It is often argued that black, indigenous, and other minoritized families are subjected to more surveillance and thus are reported disproportionately more frequently to CPS. In this case, only $5.7 \%$ of the state's population identifies as a race or ethnicity other than white and non Hispanic (Census Bureau, 2020). If diverse populations are subjected to more surveillance, it is also possible that the low rates of screened in reports could be attributed to low rates of cultural and ethnic diversity. To explore this further we looked at the state of Montana which has similarly low rates of diversity (US Census, 2019). Montana paradoxically with 
its similarly low rate of minoritized families has the highest rate of screened in neglect cases in the country (US Department of Health and Human Services, 2021).

\subsection{Vermont neglect statutes}

Vermont defines child neglect as: "harm' can occur by failure to supply the child with adequate food, clothing, shelter, or health care. As used in this subchapter, 'adequate health care' includes any medical or non-medical remedial health care permitted or authorized under State law. (Child Welfare Information Gateway; the State of Vermont, 2020, p.88)"

“Risk of harm' means a significant danger that a child will suffer serious harm by other than accidental means, which harm would be likely to cause physical injury, including as the result of any of the following:

- The production or pre-production of methamphetamines when a child is actually present.

- Failing to provide supervision or care appropriate for the child's age or development and, as a result, the child is at significant risk of serious physical injury.

- Failing to provide supervision or care appropriate for the child's age or development due to the use of illegal substances or misuse of prescription drugs or alcohol.

- Failing to supervise appropriately a child in a situation in which drugs, alcohol, or drug paraphernalia are accessible to the child" (Child Welfare Information Gateway; the State of Vermont, 2020, p.88)"

Vermont defines 'risk of harm' separately from 'neglect.' The Vermont definition of neglect can be distinguished from the definition of risk of harm in that with neglect, harm has occurred. Risk of harm is more of a preventive definition, where the child is at risk of having harm occur to them, but actual harm has not been found. 'Lack of supervision' issues are addressed in Vermont's Risk of Harm category.

Compared to other state statutes, it can be argued that Vermont statutes are aligned with the three most frequent types of definitions adopted in other states nationally. The first involves the absence of medical care and related behavioral health services, found in 45 other states; the next is the absence of food, clothing, and housing found in 44 other states. Vermont statutes also define neglect as the absence of supervision. 37 other states also have a lack of supervision clause in their statutes (DeGuerre and Briar-Lawson, 2020). However, at the outset, the Vermont neglect statute is restated as a class of harms or potential harms. The requirement that neglect must be assessed through a harm specification lens suggests the first reason why neglect rates are so low. According to state CPS leaders, rather than differentiating a maltreatment report as neglect or abuse, more rigor is required involving an assessment of such neglectful 'acts of omission.' About half of the states, including Vermont, require not just evidence but the preponderance of evidence as the threshold for substantiation of charges. Such rigor and specificity of harm, in evidential requirements are one of the several variables that may help to explain the low screened in neglect rate in Vermont.

\subsection{Organizational structures}

Vermont's CPS are housed in their Family Services Division (FSD). FSD is co-located with their Economic Services Division and their early Child Development Division. Moreover, they are all divisions within the Department for Children and Families (DCF). This Department is within the Vermont Agency of Human Services. Such co-location may create collaboration with other services, encouraging any report of maltreatment that is due to poverty-related challenges to be immediately diverted to the appropriate division of economic services. Regular collaborative meetings are conducted at the state and local level between the Economic Services Division, Child Development Division, Economic Services Division, and Office of Economic Opportunity, all located within DCF.

\subsection{Maltreatment reports}

Vermont has the highest rate of child maltreatment referrals in the nation with 171.6 per 1000 . However, unlike most other states, it screens out most of its reports of maltreatment. In fact, $79.5 \%$ of cases are screened out at intake in Vermont (Department of Health and Human Services, 2021). This is much higher than the national average of $45.5 \%$ of reports being screened out at intake. In fact, the rate of Vermont screened out cases is almost twice that of the national average of $45.5 \%$ (Department of Health and Human Services, 2021). According to the Child Maltreatment Report of 2019 (Department of Health and Human Services, 2021), Vermont only screened in 13 cases of neglect, and 11 cases of medical neglect. While lowest in the country with neglect cases, Vermont is second lowest in screened in cases of both abuse and neglect. Only South Dakota has a lower rate of screened out maltreatment cases than Vermont. In 2019, Vermont reported 851 substantiated child victims including 744 children who are white, 40 of color, and 67 unknown. This is the lowest number of substantiated child victims across all states. Demographics, including race and socioeconomic 
status for the 13 cases of neglect and 11 for medical neglect are unknown.

\section{Lessons from Vermont}

To begin to make sense of the low rate of screened in neglect cases in Vermont, the authors facilitated a focused discussion with key state child welfare leaders. From these discussions along with data analyses, the authors derived additional factors accounting for Vermont's very low neglect rates. These lessons from Vermont include the specificity of harm required to substantiate neglect, and the use of a multidimensional diversion system including an 'economic firewall,' a system of differential response (DR), and parent and child centers.

\subsection{Specificity of harm}

As one state leader noted, "I do think we are crystal clear in VT that poverty is not neglect-our definitions reflect this and our practice reflects this. We are also clear that poverty is not a reason for a child to come into DCF custody, and we have statutes to that effect as well" (Anonymous, 2020). The statutes of neglect in Vermont are more narrow, compared to other states. Vermont defines neglect as 'failure to supply a child with adequate food, clothing, shelter, or health care' (Vermont Department of Children and Families, 2020). Other states have the same neglect omission or deprivation definition as Vermont, but go on further to specify other types of neglect. An example of a more expansive definition of neglect is 'the parental failure to protect a child from sex abuse, trafficking, physical abuse, and other harms,' which is found in eighteen states (CWIG, 2019). However, while aligned with other states in attention to deprivation, Vermont's screening of reports and investigations includes the specification of the harm level. Vermont's 'risk of harm' is a separate category from neglect. Further, the state is specific in its type of 'risk of harm' with two different risk of harm categories - one is the traditional risk of harm cited above that focuses on risk of physical harm. The second is the risk of sexual harm, in which risk of sex trafficking/exposure to individuals with sexually harmful behaviors would be captured. Thus, just because a child has inadequate food, clothing, shelter, or health care, the burden is on the CPS screener and investigator to delineate the harms to the child as a result of such insufficiencies. In Vermont, rather than seeing inadequacy or insufficiency as the precondition for determining a neglect case, the issue is 'specified harms' to the child.

\subsection{Multidimensional Diversion System}

8.2.1. Economic firewall. In Vermont, family services (including CPS) and economic services (TANF) are colocated within the same department along with early childhood services, creating an economic firewall. Having the divisions co-located under the same umbrella can facilitate increased collaboration and service coordination for families who may have been reported to CPS for poverty-related reasons. This organizational structure has led to many areas of collaboration between the two divisions. In Vermont, families with economic issues are not screened into CPS for an investigation; rather they are more easily able to access services available in co-located divisions such as concrete supports through economic services, or early childhood, to address their income, housing, childcare, and related needs.

Further, all local CPS district directors have direct oversight/access to family preservation funds. These are flexible dollars that can be spent on families where there is no open case for the purpose of helping to prevent a child at risk from coming into state custody. Funds may be used to pay back rent to prevent an eviction, to help with garbage removal, laundry, food, clothing, and other basic economic assistance directly provided to the family. Concrete support in a time of need is a strengths-based protective factor that is known and exercised at the state and local levels. Interagency collaboration in this regard is key.

Vermont has a long history of interagency collaboration reaching back to the enactment of ACT 264: Coordinated Service Planning in 1990. Coordinated Services Plans involve a collaborative process between the Agency of Education and the Agency of Human Services 'intended to develop and implement a coordinated system of care so that children and adolescents will receive appropriate educational, residential, mental health and other treatment services in accordance with an individual plan (Vermont Coordinated Services Plan Act, 1990).' The planning process is unique to Vermont and speaks to the state's commitment to the preventative work of assisting vulnerable families, the majority of whom are living in poverty.

8.2.2. Differential response. DR is used by a number of states to preempt a formal maltreatment investigation of the family and instead to offer a needs assessment. Vermont has implemented DR throughout the state. According to the 2019 Child Maltreatment Report (Department of Health and Human Services, 2021), 28.8\% of Vermont's accepted or screened in referrals are diverted to the alternative response track, in which a formal investigation does not occur. The goal of DR is to increase family engagement and to meet the needs of 
families rather than to have them be subjected to a formal investigation.

An exploration of data from the National Child Abuse and Neglect Data System (NCANDS) allowed for a comparison of the number of substantiated neglect reports before and after DR was implemented. Results showed a significantly lower number of neglect reports were substantiated after DR (9.2\%) than before $\left(23.2 \%\right.$; $\left.x^{2}(1)=180.51, p<.001\right)$. Similarly, fewer substantiated cases involved neglect after DR was implemented $(4.1 \%)$ than prior to DR implementation $(7.1 \%$; $\left.\mathrm{x}^{2}(1)=54.25, p<.001\right)$. These data illuminate the potential protective influence of DR implementation on neglect in Vermont.

8.2.3. Parent-Child Centers (PCC). State CPS leaders mentioned the influence that PCCs may have on primary prevention and in providing supports to families living in poverty. Fifteen family resource centers across the state, PCCs, support and educate families with the goal of ensuring that every child has 'the opportunity to grow up healthy, happy and productive.' According to the Addison PCC (Addison County, 2020), the centers aim to:

- Strengthen families

- Help young families achieve self-sufficiency

- Prevent or alleviate major stresses on families

- Ensure that all children get the love and positive attention that they need

- Help teenagers make responsible decisions about family life

- Encourage prevention activities in our community

- Work cooperatively with other agencies in providing services

- Help other community groups establish similar programs

Although Vermont does not measure the diversion effect that the Parent and Child Centers have had on child welfare involvement, it is suggested that having this kind of help giving infrastructure in place across the state may divert families from being reported to CPS. Studies from other jurisdictions support such assumptions regarding the diversion and needs meeting effects of the Vermont Child and Parent Centers. For example, a study of Family Resource Centers in Allegheny County, PA showed benefits to families who might have otherwise been seen in the child welfare system (Wulczyn and Levy, 2018). Similarly, in San Francisco, such diversionary effects have been reported (Casey Family
Programs, 2020a, 2020b). Further, a recent report completed by Johnson Group Consulting noted the benefit of the PCCs:

'PCCs provide a community-based, multi-faceted response when risks and needs are identified. This is a resource unique to Vermont which has adapted to changes in social risk, poverty, and employment trends, and emerging evidence about what works in serving families with young children. They form a source of central intake and referral, community-team based response, and anchor for universal screening as well as home visiting and other responses to family risks (2019, p.2).'

\section{Discussion}

The portrait that emerges of Vermont involving maltreatment and neglect cases is paradoxical. Vermont, on one hand, has the highest rates of maltreatment reports per capita in the nation. One would expect from this that the screened in cases would reflect a high proportion of both abuse and neglect reports. Instead, Vermont's cases go from the highest in terms of reports to the lowest nationally in cases of neglect that are screened in for an investigation. As delineated in the focused discussion with state child welfare leaders, Vermont uses a multipronged approach with several unique 'best practices' in place. This includes the practice of specifying harms rather than omissions or insufficiencies involving basic needs, medical care, and supervision. In effect, inadequacies in meeting basic needs are subjected to an additional specification of explicit harms to the child, requiring a preponderance of evidence. Further, the use of an economic firewall, ensuring that poverty and related economic issues are not seen as constituting neglect, adds to the diversionary practices of screening out neglect cases related to poverty and economic issues. Moreover, the replacement of investigations with a DR system that addresses needs rather than incidents increases the likelihood that families with cases that could be seen as abuse or neglect are provided with services to reduce risk factors and increase protective factors. Finally, the use of statewide family supports in the form of parent and child centers may further divert families from being reported to CPS.

These practices, along with structural arrangements in cohoused divisions of Family Services/CPS and Economic Services, are reminiscent of more integrative practices of welfare income assistance and child welfare services in the 1960s. Moreover, family supports and centers are seen to be essential to the diversion of maltreatment cases.

Several caveats remain. Traditional structured decision making tools such as safety and risk assessments, or even 
predictive analytics do not deal with chronic neglect. Because investigations are incident and not chronicity based, such tools may be limited and cases of chronic neglect may go undetected. This is because Vermont, like all other states, is driven by an incident-based system of investigations and assessment. Thus chronicity, in neglect, replete with significant harm over time for children and families, remains an outstanding issue for the state of Vermont and the entire nation (Caplan et al., 2009).

A second caveat is that while Vermont uses diversion strategies for neglect cases, the outcomes remain unknown. For example, families referred to the Economic Services Division may not be sufficiently supported if they do not qualify for aid. Further, once aware of a report, it is possible that the compulsory powers of CPS do not reside in the Economic Services Division. Thus some families may avoid surveillance and help-seeking. In fact, there may be some who might worry that families and children are referred to a system of income and related support services that may not have the capacity to scrutinize for child safety.

At the outset, we hypothesized that Vermont was a positive outlier with its low rate of neglect cases. This case study offers more evidence suggesting that Vermont might indeed be a positive outlier. The intentional and relevant diversion of neglect cases into economic assistance and D.R., along with the system-wide use of Parent and Child Centers at a minimum, positions Vermont's child welfare practices as a guide to other states. Lesson drawing from Vermont becomes more urgent against a backdrop of a pre- CPS history in the US in which child welfare comprised family and income support strategies. We conclude that some of these strategic Vermont income and family support strategies could be replicated in other states and internationally.

Further research and case studies are required to understand how the states of Hawaii and Pennsylvania also have kept screened in neglect cases to a minimum of $3.5 \%$ and $7.7 \%$ respectively. It is possible that creative diversion and related supports are at work in their child welfare systems, warranting more studies.

Some might think that poverty exemptions in state statutes might further the diversion of poverty related neglect cases from being screened into CPS. We argue that such exemptions are no guarantee of such diversion and screening out of poverty related neglect reports. In fact, the Vermont case study suggests that strategic practices, including rigorous harm specification along with multisystemic, basic needs oriented diversion programs and practices are necessary.

As fears grow about the impact of the COVID-19 pandemic and economic casualties for families involving layoffs and business closures, there have been arguments made for more diversion to keep cases involving families who are impoverished from being reported to CPS for an investigation. Such fears have led to calls to defund CPS as the system is seen as another form of policing for the poor and communities of color. While Vermont is a small state, not heavily populated, and with a small percent of the population identifying as black, indigenous, people of color, there are nonetheless implications for practice particularly for states with more diverse populations.

\section{Conclusion}

Lesson drawing across the states and even cross nationally is critical as human needs mount due to the COVID-19 pandemic. Few states or nations are prepared for the level of crisis that is ensuing due to layoffs, financial and material hardship. Just as Vermont serves as an example in reaction to its handling of neglect, so too do we learn from other countries as they navigate ways to address rising economic harms to families. For example, In Canada, a university-public child welfare agency partnership developed an economic hardship screening tool to identify and rapidly address the economic needs of child welfare involved families (Fallon et al., 2020). The pandemic offers an opportunity to rethink the response to families with economic hardship and to reconfigure services that are tailored to their needs. CPS systems can be leaders in re-envisioning more economically tailored approaches and diverting cases from being screened into the child welfare system. Vermont, as a case study, offers one potential model for doing so.

\section{References}

Addison County PCC. (2020) About us. Available at: https://www.addisoncountypcc.org/about us

Anonymous. (2020). Personal Communication. (September 2020).

Berns, D., Briar-Lawson, K. and Kim, W. (2013) 'Addressing poverty as a child welfare strategy' in K. Briar-Lawson, M. McCarthy, \& N. Dickinson (eds), The Children's Bureau: Shaping a century of child welfare practices, programs, and policies, Washington D.C.: NASW Press, pp. 43-58.

Casey Family Programs (2020a) Building communities of hope, Available at: https://www.casey.org/who-weare/2020-building-communities-of-hope/ 
Casey Family Programs (2020b) On the pathway of hope, Available at: https://www.casey.org/hope./

Census Bureau (2019) U.S. Census Bureau quick facts: Montana. Available at: https://www.census.gov/quickfacts/fact/table/MT,US/PS $\underline{\mathrm{T} 045219}$

Census Bureau (2020) U.S. Census Bureau quick facts: Vermont. Available at https://www.census.gov/quickfacts/VT

Children's Bureau (2021) State and Tribal Funding. Available at https://www.acf.hhs.gov/cb/programs/state-tribalfunding

Child Welfare Information Gateway (2016) Racial disproportionality and disparity in child welfare. Washington D.C.: Administration for Children and Families, Administration on Children, Youth and Families, Children's Bureau

Child Welfare Information Gateway (2018) Acts of omission: An overview of child neglect. Available at: https://www.childwelfare.gov/pubPDFs/acts.pdf

Child Welfare Information Gateway (2019) Definitions of child abuse and neglect. Available at: https://www.childwelfare.gov/pubPDFs/define.pdf

Children's Defense Fund (2021) The state of America's children in Vermont factsheets. Available at: https://www.childrensdefense.org/state-of-americaschildren/soac-2021-factsheets/

Coulton, C., Crampton, D., Irwin, M., Spilsbury, J. and Korbin, J. (2007) 'How neighborhoods influence child maltreatment: A review of the literature and alternative pathways', Child Abuse \& Neglect, 31(11-12), pp.11171142. https://doi.org/10.1016/j.chiabu.2007.03.023

Day, E., Tach, L. and Mihalec-Adkins, B. (2021) 'State child welfare policies and the measurement of child maltreatment in the United States', Child Maltreatment, doi: https://doi.org/10.1177/10775595211006464

DeGuerre,K. and Briar-Lawson,K ( 2020) 'Policy brief: A typology of Child Neglect Statutes and exploration of rate variation among States'. University at Albany, School of Social Welfare. Unpublished paper.

Department of Health and Human Services (2021) Child maltreatment 2019. Available at: https://www.acf.hhs.gov/cb/report/child-maltreatment$\underline{2019}$

Dettlaff, A., Weber, K., Pendleton, M., Boyd, R., Bettencourt, B. and Burton, L. (2020) 'It is not a broken system, it is a system that needs to be broken: The upEND movement to abolish the child welfare system', Journal of Public Child Welfare, 14(5), pp. 500-517. doi: https://doi.org/10.1080/15548732.2020.1814542

Fallon, B., Lefebvre, R., Collin-Vézina, D., Houston, E., JohCarnella, N., Malti, T., Filippelli, J., Schumaker, K., Manel, W., Kartusch, M. and Cash, S. (2020) 'Screening for economic hardship for child welfare-involved families during the COVID-19 pandemic: A rapid partnership response', Child Abuse \& Neglect, 110. https://doi.org/10.1016/j.chiabu.2020.104706

Fluke, J., Harden, B.J., Jenkins, M. and Ruehrdanz, A. (2010) Research synthesis on racial disparities and disproportionality. Available at https://casala.org/wpcontent/uploads/2015/12/Disparities-and-

Disproportionality-in-Child-Welfare An-Analysis-of-theResearch-December-2011-1.pdf\#page $=11$

Fong, K. (2020) 'Getting eyes in the home: Child protective services investigations and state surveillance of family life', American Sociological Review, 85(4), pp. 610-638. https://doi.org/10.1177/0003122420938460

Friedman, E. and Billick, S. (2014) 'Unintentional child neglect: Literature review and observational study', Psychiatric Quarterly, 86(2), pp.253-259. https://doi.org/10.1007/s11126-014-9328-0

Grossman, F., Spinazzola, J., Zucker, M., and Hopper, E. (2017) 'Treating adult survivors of childhood emotional abuse and neglect: A new framework', American Journal of Orthopsychiatry, 87(1), pp.86-93. https://doi.org/10.1037/ort0000225

Gustafson, K. (2011) Cheating ourselves: Public Assistance and the Criminalization of Poverty. New York: NYU Press Scholarship.

Houshyar, S. (2014) Poverty and child neglect: What we know and what we need to do first. Available at: https://firstfocus.org/blog/poverty-and-child-neglectwhat-we-know-and-what-we-need-to-do

Johnson Group Consulting. (2019) Vermont's home visiting system in context. Available at: https://dcf.vermont.gov/sites/dcf/files/DCF/reports/Home -Visiting-CHINS.pdf

Kaplan, C., Schene, P., DePanfilis, D., \& Gilmore, D. (2009). 'Introduction: Shining light on chronic neglect'. Protecting Children, 24 (1), pp. 1-8.

Lansford, J., Godwin, J., Uribe Tirado, L., Zelli, A., AlHassan, S., Bacchini, D., Bombi, A., Bornstein, M., Chang, L., Deater-Deckard, K., Di Giunta, L., Dodge, K., Malone, P., Oburu, P., Pastorelli, C., Skinner, A., 
Sorbring, E., Tapanya, S. and Alampay, L. (2015) 'Individual, family, and culture level contributions to child physical abuse and neglect: A longitudinal study in nine countries', Development and Psychopathology, 27(4, part 2), https://doi.org/10.1017/S095457941500084X pp.1417-1428.

Levine, R., Dixon, S., Richman, A., Leiderman, P. and Keefer, C. (1994) Child care and culture: Lessons from Africa, Cambridge: Cambridge University Press.

Milner, J. and Kelly, D. (2020) It is time to stop confusing poverty with neglect. Children's Bureau Express. Available at: https://cbexpress.acf.hhs.gov/index.cfm?event=website.vi ewArticles\&issueid $=212$ \$ionid $=2$ \&articleid $=5474$

Padilla, J. and Summers, A. (2011) Disproportionality rates for children of color in out of home care. U.S. Department of Justice. Available at: https://www.ojp.gov/ncjrs/virtuallibrary/abstracts/disproportionality-rates-children-colorfoster-care-may-2011

Pelton, L. (1989) For reasons of poverty: A critical analysis of the public child welfare system in the United States. New York: Praeger Publishers.

Pelton, L. (2016) 'Separating coercion from provision in child welfare', Child Abuse and Neglect, 51, pp. 427-434. https://doi.org/10.1016/j.chiabu.2015.08.007

Pierce, B., Jaggers, J., Bloomquist, K., Imburgia, T., Danh, M. and Hall, J. (2018) 'Utilization of concrete services in child welfare: A mixed method analysis of a title IV-E waiver demonstration program', Journal of Public Child Welfare, 12(2), $\quad$ pp. 153-169. https://doi.org/10.1080/15548732.2017.1377139

Pryce, J., Lee, W., Crowe, E., Park, D., McCarthy, M. and Owens, G. (2019) 'A case study in public child welfare: County-level practices that address racial disparity in foster care placement', Journal of Public Child Welfare, 13(1), pp. 35-59. https://doi.org/10.1080/15548732.2018.1467354

Reich, J. (2005) Fixing families: Parents, power, and the child welfare system, New York: Routledge.

Rose, S. and Meezan, W. (1996) 'Variations in perceptions of child neglect', Child Welfare, 75(2), pp. 139-160.

Sciamanna, J. (2019) Child maltreatment 2018 report shows an increase in child abuse, Available at: https://www.cwla.org/child-maltreatment-2018-reportshows-an-increase-in-child-abuse/

Sedlak, A., Mettenburg, J., Basena, M., Petta, I., McPherson, K., Greene, A. and Li, S. (2010) Fourth national incidence study of child abuse and neglect (NIS-4): Report to Congress: Executive summary. Available at: https://cap.law.harvard.edu/wpcontent/uploads/2015/07/sedlaknis.pdf

Semanchin Jones, A., \& Logan-Greene, P. (2016) Understanding and responding to chronic.

neglect: A mixed methods case record examination. Children and Youth Services Review, 67, 212-219.

Slack, K., Berger, L. and Noyes, J. (2017) 'Introduction to the special issue on the economic causes and consequences of child maltreatment', Children and Youth Services Review, 72 , pp. $1-4$. https://doi.org/10.1016/j.childyouth.2016.11.013

US Department of Health and Human Services (2021) Child maltreatment 2019. Available at: https://www.acf.hhs.gov/cb/data-research/child$\underline{\text { maltreatment }}$

US Department of Health and Human Services (2005) Federal foster care financing: How and why the current funding structure fails to meet the needs of the child welfare field. Available at: https://aspe.hhs.gov/reports/federal-fostercare-financing-how-why-current-funding-structure-failsmeet-needs-child-welfare-field-0

Vermont Coordinated Services Plan Act no 264, H.706 (1990).

Vermont Department of Children and Families (2020) Child abuse and neglect definitions. Available at: https://dcf.vermont.gov/sites/dcf/files/FSD/Policies/50.pd f

Wulczyn, F. and Levy, B. (2018) Do family support centers reduce maltreatment investigations? Evidence from Allegheny County. Available at: https://fcda.chapinhall.org/wpcontent/uploads/2019/03/FSC-Allegheny-CountyDec2018.pdf

Wulczyn, F., Chen, L., Hislop, B. (2007) Foster care dynamics 2000-2005: A report from the multistate foster care data archive. Available at: https://fcda.chapinhall.org/wpcontent/uploads/2013/10/Foster-Care-Dynamics-20002005.pdf 